УДК 782.1

\author{
Е Санвей \\ аспирант кафедры теории музыки и фортепиано \\ Харьковской государственной академии культуры \\ odma_n@ukr.net

\section{ВОКАЛЬНЫЙ ЦИКЛ СТИХОТВОРЕНИЙ С МУЗЫКОЙ В СТРУКТУРЕ И СОДЕРЖАНИИ ОПЕРЫ САН БО «БАБОЧКА»}

Цель статьи заключается в изучении роли вокального иикла стихотворений с музыкой в структуре и содержании оперы Сан Бо «Бабочка». Научная новизна заключается в определении роли внутренних циклов в формировании трех условных актов оперного действия. Методология. В статье применены аналитический, компаративный и структурный подходы к рассматриваемому музыкальному материалу. Выводы. Опера как художественное целое представляет собой мета-цикл стихотворений с музыкой, вбирающий в свой состав шесть взаимодействующих между собой малых (внутренних) циклов, выполняющих в пределах оперы превращений роль её трёх условных актов. Процесс циклообразования в музыкальной драме превращения «Бабочка» отличает наличие разновидностей входящих в её состав внутренних ииклов и обвединяющих их закономерностей. Внутренние вокальные циклы стихотворений с музыкой, организованные в циклы циклов, а в итоге - мета-цикл, охватывающий оперу Сан Бо как музыкальную драму превращений, отражают её важнейшие жанрово-стилевые свойства, отражают свойственную ей философскую концепиию искупительной метаморфозы.

Ключевые слова: музыкальная драма превращений, номерная структура оперы, внутренний (малый) вокальный цикл, жанр стихотворения с музыкой, условные акты в структуре оперного действия.

E Syanvey graduate student of the of the Theory of music and piano department of The Kharkiv State Academy of Culture

Vocal cycle of poems with music in the structure and content opera San Bo "Butterfly"

The purpose of this article consists in studying of a role of a vocal cycle of poems with music in structure and contents of the opera of San Bo «Butterfly». The scientific novelty consists in definition of a role of internal cycles in formation of three conditional acts of opera action. Methodology. In article analytical, komparative and structural approaches to the considered musical material are applied. Conclusions. The opera as an artistic whole represents the meta-cycle of poems with music incorporating six small (internal) cycles interacting among themselves which are carrying out a role of her three conditional acts within the 
opera of transformations into the structure. Process of cyclic formation in the musical drama of transformation «Butterfly» distinguishes existence of kinds of the internal cycles and regularities uniting them which are its part. The internal vocal cycles of poems with music organized in cycles of cycles, and as a result the meta-cycle covering the opera of San Bo as the musical drama of transformations reflect its major genre and style properties, reflect the philosophical concept of an expiatory metamorphosis peculiar to her.

Keywords: the musical drama of transformations, number structure of the opera, an internal (small) vocal cycle, a poem genre with music, conditional acts in structure of opera action.

Е Сяньвей, аспірант кафедри теорії музики і фортепіано Харківської державной академії культури

Вокальний цикл віршів із музикою у структурі і змісті опери Сан Бо «Метелик»

Мета статті полягає у вивченні ролі вокального циклу віршів з музикою в структурі і змісті опери Сан Бо «Метелик». Наукова новизна полягає у визначенні ролі внутрішніх циклів у формуванні трьох умовних актів оперної діi. Методологія. У статті використані аналітичний, компаративний та структурний підходи до розглянутого музичного матеріалу. Висновки. Опера як художне ціле являє собою метацикл віршів з музикою, що вбирає в свій склад шість взаємодіючих між собою малих (внутрішніх) циклів, що виконують в межах опери перетворень роль ї̈ трьох умовних актів. Процес ииклоутворення в музичній драмі перетворення «Метелик» відрізняє наявність різновидів, що входять до їі складу внутрішніх процедур та що об'єднують їх закономірності. Внутрішні вокальні цикли віршів з музикою, організовані в цикли циклів, а в підсумку - метацикл, що охоплює оперу Сан Бо як музичну драму перетворень, відображають їі найважливіші жанрово-стильові властивості, відображають властиву ій філософську концепцію спокутної метаморфози.

Ключові слова: музична драма перетворень, номерна структура опери, внутрішній (малий) вокальний иикл, жсанр вірша з музикою, умовні акти в структурі оперної діï.

Актуальность исследования. Образцы новейшего китайского искусства, перестав быть «закрытыми» от влияний извне художественными целостностями, вбирают разновекторные европейские традиции, оставаясь воплощением национального духа. В результате синтез разнородного предстает в качестве того художественного метода, что определяет самую сущность художественных произведений новейшего Китая. При этом опера как тот жанр, что в силу своей природы изначально тяготел к взаимодействию искусств и традиций, является той художественной субстанцией, в которой образование новых музы- 
кально-сценических целостностей подчинено сложнейшим процессам взаимодействия разнонациональных и разновременных тенденций. В итоге опера предстает как художественная целость, что являет собой синтез традиций разнородного происхождения. Изучение основ жанро-, смысло- и формообразующих черт китайской оперы начала XXI века - важнейшая задача современного музыковедения.

Цель данной статьи заключается в изучении роли вокального цикла стихотворений с музыкой в структуре и содержании оперы Сан Бо «Бабочка».

Научная новизна заключается в определении роли внутренних циклов в формировании трех условных актов оперного действия.

Изложение основного материала. Структура оперы Сан Бо «Бабочка» (2008) указывает на свойственные ей жанровые признаки европейской номерной оперы. Каждый из ее 14 номеров представляет собой самодостаточный художественный эпизод, фрагмент оперного действия, воплощенного в поэтически-символической форме. В опере Сан Бо пронумерованные «фрагменты» представляют собой либо вокальную миниатюру, либо ансамблевую сцену [5]. Хотя композитор, вопреки традициям европейского прообраза, не обозначает жанровую принадлежность оперных номеров, жанровые свойства каждого из них представлены весьма определенно. Эта особенность позволяет, несмотря на отсутствие авторских «жанровых имен» [4], установить их аналитическим путем. Номера оперы Сан Бо в своем большинстве представляют собой арии (монологи) и дуэтно-диалогические сцены.

Как и в европейской номерной опере, каждый из номеров «Бабочки» - музыкальной драмы превращений, - являет собой выражение лирического чувства героев, представая в качестве лирической кульминации. Подобно тому, как это было свойственно неаполитанской opera-seria, по наблюдению Т. Ливановой [3], драматургия оперы Сан Бо являет собой череду лирических кульминаций. Значение лирической кульминации оперные номера «Бабочки» обретают в контексте драматургического развития того или иного персонажа, становления асобытийного сюжета искупительной драмы превращений.

Своеобразие драматургии китайской номерной оперы, отличающей её от закономерностей неаполитанской opera-seria, связано с отсутствием речитативов, имеющих функцию краткого изложения действия, вынесенного за пределы сценического показа, предваряющих арии (дуэты) как лирические кульминации. Свойственные опере 
Сан Бо минимализация событий, обилие «пропусков» в развертывании сюжета, его раскрытие посредством символических, взаимодействующих между собой смысловых рядов - исключают речитативы. Каждый «номер» оперы Сан Бо предстает как предварение или лирическое обобщение события, свершившегося «за скобками» сценического действия музыкальной драмы превращений. Абсолютизация лирического начала ведет к сплетению сложно организованных метафор. Отсутствие речитативов как таковых не означает отсутствия речитативности: высказывания героев оперы основаны на взаимодействии арийно-ариозного стиля и черт parlando.

Наряду со свойствами номерной оперы «Бабочка» Сан Бо обладает чертами романтического театрализованного полиперсонажного вокального цикла. Основой вокального цикла, обеспечивающей жанровое единство оперы, является стихотворение с музыкой, обладающее в истории современной китайской музыки весомым значением [6]. Рассредоточенные в оперном целом шесть внутренних (малых) вокальных циклов стихотворений с музыкой, попарно объединены в циклические группы - циклы циклов, которые уподобляются трём условным действиям в структуре одноактной оперы. Оперное целое предстает в роли метацикла, объединяющего в единой циклической целостности внутренние (малые) циклы. Наряду с жанровыми чертами лирической оперы музыкальная драма превращений обладает признаками жанра второго плана - вокального цикла, структурной единицей которого является стихотворение с музыкой.

В клавире оперы отсутствуют авторские обозначения, определяющие количество действий, жанровые функции номеров (такие как пролог, вступление, финал; монолог, ансамбль, ария). Подобное композиторское оформление оперы свидетельствует об определенном композиторском аскетизме, сгущении атмосферы тайны, недосказанности, движущей развитием музыкально-поэтического действия. Одноактная опера организована в соответствии с развертыванием этапов лирической драмы: экспозиция образов героев обладает чертами завязки, развитие приводит к кульминации действия, конфликту и развязке. Таинственность определяет развертывание музыкальной драмы, определяя «рисунок» развития образов героев.

Жанровыми чертами стихотворения с музыкой как жанровой «опоры» оперы Сан Бо являются: взаимодействие философского, пейзажного начал и описание перемен внутреннего мира героев, их способность к авторефлексии, отстраненность от развития завуали- 
рованного сюжета. Стихотворения с музыкой, пребывая «над действием» музыкальной драмы, обретают значение лирических отступлений в процессе развития действия.

Стихотворениям с музыкой, наряду с общими жанровыми и драматургическими функциями, присущи и различия. Они могут быть как сольно-монологическими, так и дуэтно-диалогическими; как представлять собой законченный музыкальный номер (сцену), так и являться его фрагментом, будучи частью ансамбля, с которым, как правило, связаны конфликтные этапы в оперной драматургии. В опере возникает рассредоточенный вокальный цикл стихотворений c музыкой, благодаря которому философско-поэтическая авторефлексия героев оперы, поднимая их «над драмой» и отчуждая от оперного действия, отражает преобразования внутреннего мира героев и творимой ими драмы. Наряду с функцией «отчуждения» от драмы оперным стихотворениям с музыкой присуща включенность в свершающееся превращение, происходящее то ли в душе героя (героини), то ли в общем процессе становления музыкальной драмы как череды метаморфоз.

Важнейшую роль играет триединство принципов метафоричности, метаморфозы и мнимости происходящего. Если метафоричность обусловлена поэтической атмосферой действия, метаморфоза - семантикой превращений, то мнимость происходящего - присущей китайской философии установкой на достижение в процессе восприятия мира ощущений кажущейся реальности, выражаемой посредством высказывания, согласно которому определенный предмет «то ли есть, то ли нет...». Мнимость ярко представлена в ответе Бродячего Поэта Старому Отцу из № 5 «Ночь»: «...Есть Бабочки, которые и не живут, и не умирают...». Эта фраза - ключевая в опере, в ней содержится расшифровка действия, направленного на искупление. Преодоление существования «между жизнью и смертью» цель проклятого рода. Её достижение возможно ценой самопожертвования Влюбленных Бабочек, осуществляемого в финальном № 14 (дуэте Лян Женбо и Цу Иньтей): «Любовь - это путь борьбы». Здесь исчезает мнимость, что характеризовала становление драмы превращений.

Главный герой оперы - Поэт, не знающий пристанища, ищущий смысл жизни в безначальном и бесконечном путешествии, в философско-поэтической форме запечатлевает впечатления от прохождения стадий превращения в процессе жизненного пути, формируя 
поэтическую атмосферу художественного целого. Не случайно, что в партии Лян Женбо формируется жанровая специфика стихотворения с музыкой: Поэт задает «тон» философско-поэтического осмысления мира, сопоставления своего «Я» и окружающего мира. В партии Лян Женбо единожды в опере возникает соотношение сольного высказывания с жанровой категорией стихотворения. № 7 определяет жанровую парадигму развития лирической оперы. С жанром стихотворения с музыкой связывается философско-поэтическое осмысление мира, авторефлективное самопостижение, отчуждение от искупительной драмы превращений, сообщение персонажам функции «героев над действием» в её свершении.

Два первых номера - «Поэт-Скиталец», в котором представлен образ Лян Женбо, и «Свадьба», где запечатлен образ «дочери Бабочки» Цу Иньтей, мечтающей выйти замуж за «того, кому все дозволено», - выполняют функцию экспозиции образов главных героев. Диптих, образованный стихотворениями с музыкой, открывает череду подобных жанровых образований, пронизывающих оперную драматургию. Сольные вокальные миниатюры являют собой портреты-автохарактеристики, монологи-исповеди героев, объединенных идеей поиска смысла своего предназначения. Жизненная цель Поэта-Скитальца сопряжена с обретением пристанища, достижение которого желанно после длительного странствия, созерцания космических миров. Предназначение Цу Иньтей - выйти замуж за того, кто способен осуществить искупительное превращение.

Объединяют экспозиционные монологи общие черты, представленные словно бы в зеркальном отражении. Среди них - вопросы, обращенные к безмолвному окружающему героев миру. Вопросы подобного рода придают первым сольным высказываниям черты внутреннего, драматического монолога.

Структурной особенностью функционирования стихотворений с музыкой в музыкальной драме превращений является возникновение ряда внутренних (малых) циклов, обусловленных логикой смыслообразования, особенностями композиторской интерпретации жанрового прообраза. При этом внутрициклические образования (порой объединенные в своеобразные циклы циклов) соответствуют членению оперы на условные акты.

№ 1 и $2-$ первый внутренний цикл сольных стихотворений с музыкой, диптих, являющий собой экспозицию образов главных героев (Лян Женбо и Цу Иньтей). 
№ 3, 4, 5 («Новобрачная», «Кто он?», «Ночь») - триптих ансамблевых номеров, в которых стихотворения с музыкой (как сольные, так и дуэтные) образуют фрагменты целого, в результате чего данный внутренний цикл стихотворений с музыкой обретает черты рассредоточенного.

Взаимодействие двух первых малых циклов, первый из которых - сольный диптих, а второй отличается тем, что входящие в его структуру стихотворения с музыкой вписаны в качестве фрагментов в организацию ансамблевых сцен триптиха, свидетельствует о возникновении цикла циклов (первой пары внутренних циклов), способствующего образованию условного I акта оперы превращений. Финал I акта ознаменован судьбоносным признанием Поэта о похищении Иньтей - Новобрачной. Так происходит подтверждение сакральной функции героя как Жениха-Искупителя рода Бабочек от проклятия, героя, избравшего и похитившего Новобрачную, связав с ней, таким образом, функцию жертвоприношения.

№ 6 «Известие» (монолог Цу Иньтей), № 7 «Что есть любовь» (монолог Лян Женбо) и № 8 «Желание вина» (монолог Спрей-дитя) образуют второй внутренний цикл сольных стихотворений с музыкой и третий внутренний цикл в общем процессе циклообразования. С данным триптихом сольных стихотворений с музыкой связано начало II условного акта оперы превращений.

№ 9 «Почему? Позволь мне любить тебя!» - ансамблевая сцена, организованная в виде четырех монологических стихотворений с музыкой (Цу Иньтей, Лян Женбо, Цу Иньтей, Старый Пьяница), являющая собой второй внутренний цикл ансамблевого типа и четвертый внутренний цикл в общей структуре циклообразования в опеpe. Своеобразие данного внутреннего цикла, состоящего из четырех сольных стихотворений с музыкой, заключается в том, что он «вписан» в пределы одного номера. С точки зрения структуры оперного целого четвертый внутренний цикл выполняет роль финала II акта.

Таким образом, условный II акт оперы образует взаимодействие двух внутренних циклов (второй цикл циклов, вторая пара внутренних циклов) - триптиха сольных номеров (№ 6-8) и тетрады монологических стихотворений с музыкой, вписанных в структуру ансамблевой сцены (№ 9). В результате условное II действие оперы предстает как последовательность семи сольных стихотворений с музыкой.

№ 10 «В кондитерской» (сцена галлюцинаций Маленькой Сиротки), № 11 «Решение судьбы» (монолог Старого Отца, предоставля- 
ющего судьбе предопределять судьбу рода Бабочек), № 12 «Сердце» (лирический монолог Поэта о противоречиях любви) и № 13 «Правда» (предфинальный монолог Старого Пьяницы о предыстории событий, раскрывающий причину проклятия рода Бабочек) - образуют пятый внутренний цикл монологических стихотворений с музыкой. С данной сольной тетрадой связывается функция начала III условного действия оперы превращений.

№ 14 «Любовь - это путь борьбы» - искупительный финал оперы превращений, сконструированный в виде последовательности четырех лирических стихотворений с музыкой (двух сольных и двух дуэтно-диалогических). Торжество любви неотделимо от кульминации идеи искупления: Цу Иньтей и Лян Женбо - это влюбленные Бабочки, которые жертвуют собою во имя спасения проклятого рода. № 14 , подобно № 9, являет собой тетрадно организованный внутренний цикл в пределах финальной ансамблевой сцены. В качестве исходного прообраза финала оперы превращений следует назвать её экспозицию - первый внутренний цикл сольных стихотворений с музыкой, выполняющий функцию экспозиции образов главных героев произведения. Помимо этого, следует учесть, что у финального внутреннего цикла есть и иные прообразы. Это монологи влюбленных героев, открывающие 3-й внутренний цикл стихотворений с музыкой (№ 6 и 7), в котором впервые осушествлена «зеркальная» перестановка последовательности расположения лирических портретов Лян Женбо и Цу Иньтей, и связанная с последующим раскрытием их внутреннего мира последовательность сольных сцен из ансамблевого № 9.

Две по-разному организованные сольные тетрады стихотворений с музыкой (№ 10-13 и № 14) - третья пара вокальных циклов стихотворений с музыкой, третий цикл циклов составляют заключительное III условный акт оперы Сан Бо «Бабочка» как драмы превращений.

Выводы. Шесть внутренних вокальных циклов стихотворений с музыкой, в той или иной степени (целостно или фрагментарно), охватывают все 14 номеров музыкальной драмы превращений. Попарное объединение внутренних циклов стихотворений с музыкой ведет к формированию трех циклов циклов, трех условных актов оперы как музыкальной драмы превращений. Лишь отдельные эпизоды оперы, входящие в состав её ансамблевых сцен (в пределах № 3, 4 и 5), в которых действенное начало несколько превалирует над лирическим созерцанием, остаются вне её внутрициклической организации. В итоге опера как художественное целое представляет собой мета- 
цикл стихотворений с музыкой, вбирающий в свой состав шесть взаимодействующих между собой малых (внутренних) циклов, выполняющих в пределах оперы превращений роль её трёх условных актов.

Процесс циклообразования в музыкальной драме превращения «Бабочка» отличает наличие разновидностей входящих в её состав внутренних циклов и объединяющих их закономерностей.

Шесть внутренних циклов стихотворений с музыкой, введенных в структуру музыкальной драмы превращений, следует разделить на группы на основе дифференциации разновидностей композиторской трактовки жанровых единиц и их функционирования в структуре оперного целого. В роли критериев дифференциации внутренних циклов стихотворений с музыкой на группы должны предстать системные различия в их композиторской трактовке и функционировании в оперном целом.

Так, внутренние циклы следует разделить на сольные и ансамблевые. Первую группу внутренних циклов стихотворений с музыкой образуют те три из них, которые основаны на последовательности самостоятельных сольных стихотворений с музыкой (№ 1, 2; 6, 7, 8; $10,11,12,13)$. Закономерностью, присущей данной категории, является постепенное увеличение количества номеров в циклах: от двух в первом из них, к трём - во втором, и к четырем - в заключительном. Разрастание количества номеров возникает за счёт вовлечения в сольные циклы новых действующих лиц.

Вторую группу составляют три цикла стихотворений с музыкой, которые функционируют в пределах ансамблевых сцен (№ 3-5; № 9; № 14). В отличие от внутренних циклов из сольных стихотворений с музыкой, число которых от цикла к циклу разрастается, количество номеров, представляющих стихотворения с музыкой, входящих в ансамблевые сцены, сокращается от трёх в первом цикле до одного во втором и третьем. Наряду с сокрашением количества номеров, образующих внутренние циклы стихотворений с музыкой в сфере оперных ансамблей, наблюдается разрастание их внутренней структуры (от трёх стихотворений в первом внутреннем цикле к четырем во втором и третьем).

Показательно числовое соответствие сольных и ансамблевых внутренних циклов: каждый представляют по три малых цикла. Взаимодействие сольных и ансамблевых циклов осуществляется на основе альтернации: после каждого малого сольного цикла следует ансамблевый малый цикл стихотворений с музыкой. Организации вну- 
тренних вокальных циклов присуща общая закономерность: чередование сольных и ансамблевых внутренних циклов.

Для каждого из выявленных трёх условных актов оперы общим свойством является соотношение их первых половин с сольными вокальными циклами, а заключительных - с ансамблевыми. Так обнаруживается параллель с европейской классико-романтической оперой (например, моцартовской, россиниевской), для организации которой характерно конструирование первых половин актов в виде сольных экспозиций героев, а финалов действий - на основе подключения всех участников предыдущих сцен.

В структуру ансамблевых номеров входят сольные и дуэтно-диалогические стихотворения с музыкой. Следует различать ансамблевые номера и на основе того признака, насколько общекачественными в их масштабах являются жанровые признаки стихотворения с музыкой. В этом случае среди ансамблевых номеров следует выделить те, в которых стихотворения с музыкой являются фрагментами в оформлении их целостности (например, № 5), а также и такие, структура которых целиком представляет стихотворение с музыкой, в результате чего они представляют собой своего рода вокальные циклы (№ 9 и 14). В отличие от сольных внутренних циклов стихотворений с музыкой ансамблевым вокальным циклам присущи различные принципы организации.

Следующим уровнем процесса циклообразования в опере является укрупнение внутренних циклов. Не только принцип парности (попарное объединение в границах каждого из трёх условных оперных действий сольного и ансамблевого внутренних циклов), но и принцип триадичности способствуют утверждению логики циклообразования в опере. Принцип триадичности проявляется во взаимодействии двух больших рассредоточенных циклов, один из которых включает в свой состав три внутренних сольных цикла, другой - три ансамблевых. Так возникает метацикл, охватывающий масштаб всей оперы. Опере свойственно взаимодействие одночастности и цикличности, что является свидетельством преломления в ней жанровых черт романтической поэмности.

Внутренним циклам стихотворений с музыкой присуща важнейшая жанровая черта музыкальной драмы превращений - метаморфоза, находящая отражение в смене имён-функций героев. В № 2 образ Бродячего Поэта обретает новый сакральный аппелятив - «Тот, кому все можно» (в данном художественном контексте соответствует имени- 
функции Жених-Искупитель); тогда как «Бабочки дочь» в № 5, завершающем второй внутренний цикл стихотворений с музыкой, получает новое имя-функцию - Новобрачная. Имена-функции, отображая метаморфозы в структуре внутреннего мира Влюбленных Мотыльков, предопределяют дальнейший путь развития музыкальной драмы превращений: пожертвовав собой, они освобождают от проклятия род Бабочек. Финальное превращение-искупление свершилось.

Внутренние вокальные циклы стихотворений с музыкой, организованные в циклы циклов, а в итоге - метацикл, охватывающий оперу Сан Бо как музыкальную драму превращений, отражают её важнейшие жанрово-стилевые свойства, отражают свойственную ей философскую концепцию искупительной метаморфозы.

\section{СПИСОК ЛИТЕРАТУРЫ}

1. Алексеев В. Китайская литература: избр. тр. М.: Наука, 1978. 596 с.

2. Коннов В. Песни Гуго Вольфа. М.: Музыка, 1988. 96 с.

3. Ливанова Т. История западно-европейской музыки до 1789 года: в 2 т. T. 1: По XVIII в. М.: Музыка, 1983. 696 с.

4. Назайкинский Е. Стиль и жанр в музыке: учебное пособие для студ. высш. учеб. завед. М.: Владос, 2003. 248 с.

5. Рощенко Е. Число и имя в новой мифологии музыкального романтизма (нумерологический и ономатологический методы анализа музыки): Харьков: ХНУРЕ, 2004. 288 с.

6.У Хун Юань. Китайская художественная песня: история и теория жанра: дис. ... канд. искусствоведения: 17.00.03. Харьков, 2016. 231 с.

\section{REFERENCES}

1. Alekseev, V (1978). Chinese Literature: selected works. Moscow. Nauka [in Russian].

2. Konnov, V. (1988). The Songs of Hugo Wolf. Moscow. Music [in Russian].

3. Livanova, T (1983). The history of Western European music until 1789. - In 2 vols. Vol. 1. In the eighteenth century. Moscow: Music [in Russian].

4. Nazaikinsky, E (2003). Style and genre in music: Moscow. Vlados [in Russian].

5. Roshchenko, E (2004) The number and name in the new mythology of musical romanticism (numerological and onomatological methods of music analysis). Kharkov. KhNURE [in Russian].

6. U Hung Yuan (2016). Chinese art song: history and theory of the genre: Candidate'sthesis - Kharkov [in Russian].

Стаття надійцла до редакції 01.03.2017

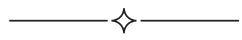

